\title{
Notes on the vocalizations of Chiguanco Thrush (Turdus chiguanco)
}

Peter Boesman

In the following we briefly analyze and compare voice of the three races of Chiguanco Thrush (Turdus chiguanco). We also try to quantify the extent of any vocal differences using the criteria proposed by Tobias et al. (2010), as a support for taxonomic review.

We have made use of sound recordings available on-line from Xeno Canto (XC).

chiguanco/conradi has a song which typically consists of 2-3 fairly melodious notes followed by one or a few higher-pitched squeaky notes. The 2-3 notes are not identical but show a similar shape. As an overall result, the phrase usually sounds very simple.

Some examples:

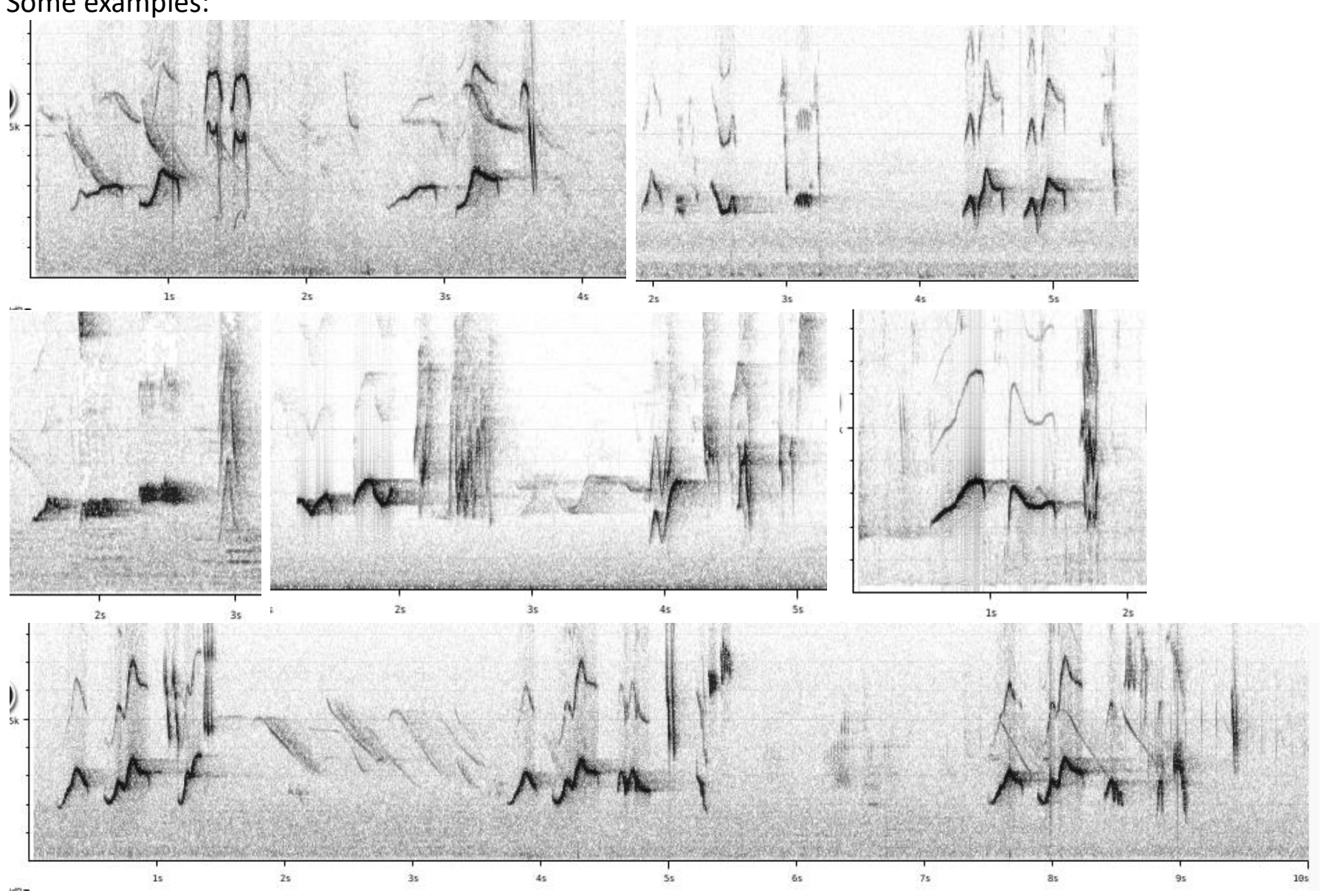



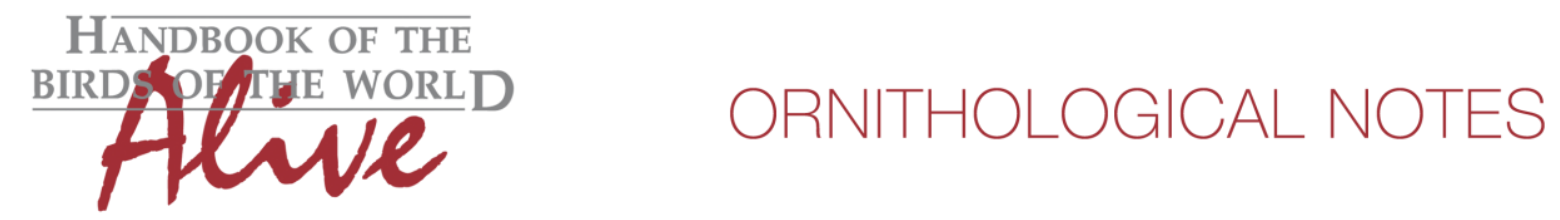

anthracinus has a song which typically consists of 4-7 melodious notes (harmonics less visible than in previous group, thus sounding purer) followed by one or a few higher-pitched squeaky notes. The 4-7 notes are not identical but show a similar shape. Notes are slightly shorter and given at a more rapid pace than previous group (typically c. 4 notes/s vs. 2 notes/s). Notes often go alternating up and down in pitch. As an overall result, the phrase usually sounds much more melodious and more complex than previous group.

Some examples:
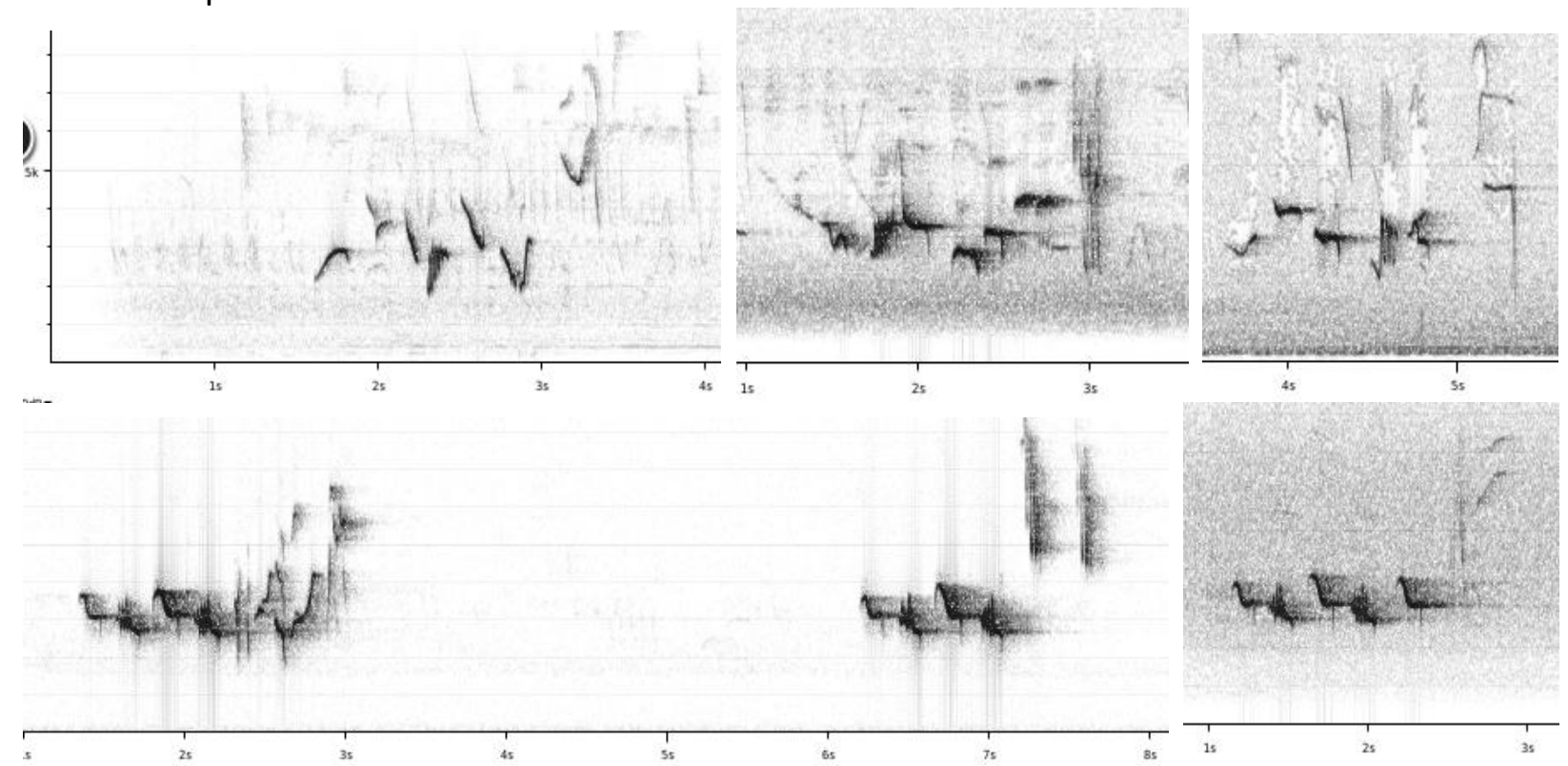

Occasionally a single phrase of either group may be difficult to assign to the correct group, but when looking at several phrases of a song, the identification is always feasible.

Vocal differences are thus quite obvious, and can be quantified as follows: anthracinus has more whistled notes in a song phrase (score 2), notes are shorter in duration (score 1-2) and are given at a higher pace (score 2). When applying Tobias criteria, this would lead to a total vocal score of about 3-4.

We haven't analyzed call notes, of which there are quite some different types. Additional differences may be found here.

This note was finalized on 19th April 2016, using sound recordings available on-line at that moment. We would like to thank in particular the sound recordists who placed their recordings of song for this species on XC: Israel Aragon, Peter Boesman, Oswaldo Cortes, Carlos Ferrari, Manuel Grosselet, Niels Krabbe, Frank Lambert, Bernabe Lopez-Lanus, Aidan Maccormick, Sjoerd Mayer, Leonardo Ordoñez-Delgado, Andrew Spencer, Joseph Tobias and Willem-Pier Vellinga. 


\section{References}

Tobias, J.A., Seddon, N., Spottiswoode, C.N., Pilgrim, J.D., Fishpool, L.D.C. \& Collar, N.J. (2010). Quantitative criteria for species delimitation. Ibis 152(4): 724-746.

\section{Recommended citation}

Boesman, P. (2016). Notes on the vocalizations of Chiguanco Thrush (Turdus chiguanco). HBW Alive Ornithological Note 307. In: Handbook of the Birds of the World Alive. Lynx Edicions, Barcelona. (retrieved from http://www.hbw.com/node/1251764 on 15 October 2016). 